\title{
Fatigue behavior of Ti-15Mo-5Zr-3Al $\beta$-type titanium alloy with surface hardened layer induced by annealing in nitrogen gas
}

\author{
K. Tamada ${ }^{1}$, Y. Uematsu ${ }^{1}$, T. Kakiuchi ${ }^{1}$, M. Akita ${ }^{2}$, M. Nakajima ${ }^{3}$ \\ \& Y. Nakamura ${ }^{3}$ \\ ${ }^{1}$ Department of Mechanical Engineering, Gifu University, Japan \\ ${ }^{2}$ Faculty of Engineering, Gifu University, Japan \\ ${ }^{3}$ Toyota National College of Technology, Japan
}

\begin{abstract}
The bulk $\beta$-type titanium alloy, Ti-15Mo-5Zr-3Al, was annealed in nitrogen gas at $1473 \mathrm{~K}\left(1200^{\circ} \mathrm{C}\right)$ for 0.5 and 1 hour in order to enhance the hardness near the specimen surface. Vickers hardness near the surface reached about $480 \mathrm{HV}$, whilst that of the matrix was $311 \mathrm{HV}$. The increase of hardness was due to the solid solution of nitrogen, precipitation of needle-like $\alpha$-phases and precipitation of nitrides, TiN. Tensile and four-point bending fatigue tests were conducted, and the nitrogen-gas-annealed specimens had lower tensile and fatigue strengths than the untreated ones. In the annealed specimens, brittle fracture along grain boundaries took place under both static and fatigue loading conditions. EDX analysis revealed that hard and thin TiN layers precipitated along the grain boundaries and their brittle fracture had detrimental effect on the static and fatigue strengths. Subsequently, re-solution treatment at $1123 \mathrm{~K}\left(850^{\circ} \mathrm{C}\right)$ was applied to the nitrogen-gas-annealed specimens in order to dissolve TiN along grain boundaries into matrix. However, tensile and fatigue strengths did not recovered to those of untreated ones because TiNs were not dissolved by the resolution treatment.

Keywords: fatigue, $\beta$-type titanium alloy, annealing in nitrogen gas, fatigue crack initiation.
\end{abstract}




\section{Introduction}

Titanium (Ti) alloys are attractive as light weight structural materials because of their light weight, high specific strength, high corrosion resistance and so on. Especially, $\beta$-type Ti alloys have low elastic modulus around 50GPa and are expected as biomaterial because their elastic modulus is close to that of human bone. However, the strengths of $\beta$-type Ti alloys are lower than those of $\alpha$-type ones. Thus, aging treatments are applied to $\beta$-type $\mathrm{Ti}$ alloys in general to precipitate $\alpha$-phase and enhance mechanical properties, whilst the precipitation of $\alpha$-phase increases elastic modulus. Recently, annealing in nitrogen gas at high temperature is applied to steel sheets to increase strengths and corrosion resistance by the solid solution of nitrogen into matrix [1-3]. This procedure is believed to be different from conventional nitriding because main target of the annealing is not precipitation of nitride but solid solution of nitrogen. Ando et al. applied this procedure to $\beta$-type Ti alloy thin sheet and successfully increased the hardness [4]. In the present study, the annealing in nitrogen gas was applied to the bulk $\beta$-type Ti alloy as a surface treatment. Using the specimens annealed in nitrogen-gas, four-point bending fatigue tests were conducted and the effect of the surface treatment on the fatigue behavior was investigated.

\section{Experimental procedure}

\subsection{Materials and specimens}

The material used is the $\beta$-type titanium alloy, Ti-15Mo-5Zr-3Al. The asreceived material was solution treated at $1123 \mathrm{~K}\left(850^{\circ} \mathrm{C}\right)$ followed by water quenching to make the microstructure full $\beta$-phases. The four-point bending specimen shown in Fig.1 was machined from the solution-treated materials. The specimen surface was polished by the emery paper with the grade of \#2000 and finally mirror finished by buff polishing. Hereafter, these samples are notified as ST (Solution Treatment) specimens. ST specimens were annealed in nitrogen gas at the temperature of $1473 \mathrm{~K}\left(1200^{\circ} \mathrm{C}\right)$ for 0.5 or 1 hour. The pressure of nitrogen gas was controlled to be $1 \mathrm{MPa}$ at $1473 \mathrm{~K}$. These samples are classified as AN (Annealing in Nitrogen gas) specimens. Subsequently, the AN-1h specimens were annealed again at $1123 \mathrm{~K}\left(850^{\circ} \mathrm{C}\right)$ followed by water quenching for redissolution of nitrides. These samples are notified as AN-RST (Re-Solution Treatment) specimens.

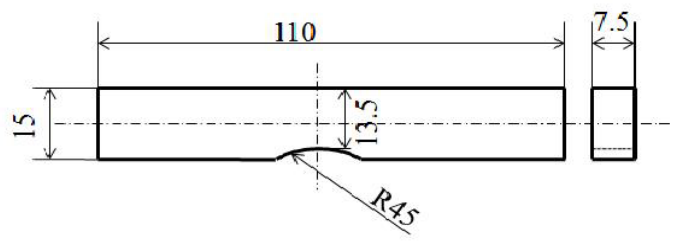

Figure 1: Configuration of fatigue specimen. 


\subsection{Experimental methods}

Four-point bending fatigue tests were carried out using an electro-hydraulic fatigue testing machine with the capacity of $98 \mathrm{kN}$. Fatigue test condition was the test frequency, $f=10 \mathrm{~Hz}$ and the stress ratio, $R=0.1$. The precipitates were analyzed by an EDX (Energy Dispersive X-ray spectrometry) method, and phase analysis was carried out by EBSD (Electron BackScatter Diffraction) method.

\section{Results and discussion}

\subsection{Microstructures}

The microstructure of the base metal is revealed in Fig. 2(a), consisting of full $\beta$ phases because the solution treatment was carried out at $1123 \mathrm{~K}$ which was higher than the $\beta$-transus temperature, $1058 \mathrm{~K}\left(785^{\circ} \mathrm{C}\right)$. The average grain size was $44 \mu \mathrm{m}$. The subsurface microstructure of $\mathrm{AN}-0.5 \mathrm{~h}$ specimen was also full $\beta$ phases as shown in Fig. 2(b), whilst the enlargement of grains occurred due to the higher annealing temperature of $1473 \mathrm{~K}$, where the average grain size was $640 \mu \mathrm{m}$. Further enlargement took place in $\mathrm{AN}-1 \mathrm{~h}$ specimen due to the longer annealing period, resulting in the average grain size of $942 \mu \mathrm{m}$. AN-RST specimen had slightly smaller grain size of $840 \mu \mathrm{m}$ than $\mathrm{AN}-1 \mathrm{~h}$ because of the recrystallization. The microstructures near specimen surfaces of AN-0.5h and AN-RST specimens are shown in Fig. 3(a) and (b), respectively. In AN-0.5h specimen (Fig. 3(a)), a white layer with the thickness of $30 \mu \mathrm{m}$ was formed at the
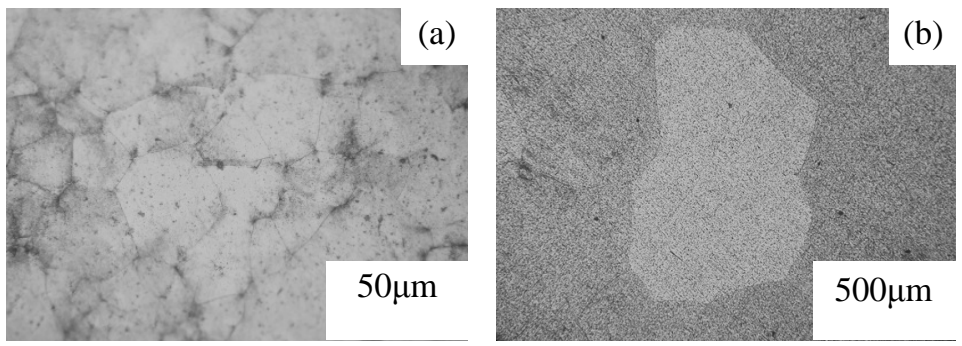

Figure 2: $\quad$ Microstructures of materials: (a) ST, (b) AN-0.5h.
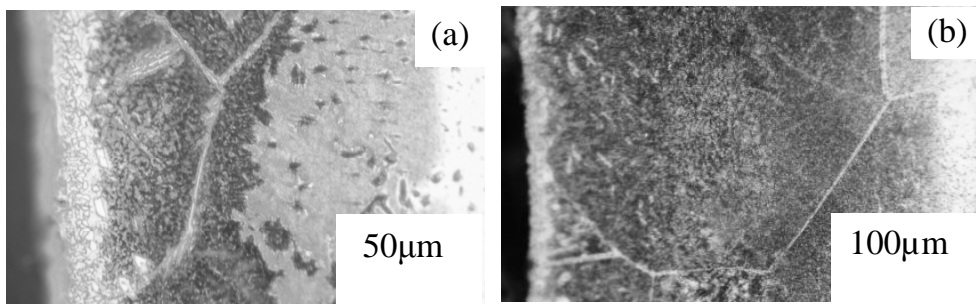

Figure 3: $\quad$ Microstructures materials near surfaces: (a) AN-0.5h, (b) AN-RST. 
topmost surface. It is assumed that the thin white layer was TiN based on the EDX analysis.

Widmannstaetten structure consisting of needle-like $\alpha$ and $\beta$-phases was formed under the white layer over the depth of $100 \mu \mathrm{m}$. Re-solution treatment thinned the white layer as shown in Fig. 3(b), whilst the Widmannstaetten layer became thicker over the depth of a few hundred microns. It should be noted that the prior $\beta$ grain boundaries are recognized as the white lines in both $\mathrm{AN}-0.5 \mathrm{~h}$ and AN-RST specimens.

\subsection{Mechanical properties}

The mechanical properties of the base metal, AN-0.5h and AN-RST specimens are summarized in Table 1. AN specimens has lower tensile strengths, elongation and reduction of area than the base metal irrelevant to the re-solution treatment. The hardness profiles from the surface are shown in Fig.3. The hardness near the surface was well increased from HV311 to around HV480 in both AN-0.5h and $\mathrm{AN}-1 \mathrm{~h}$ specimens. The surface hardness was nearly the same irrespective of annealing time in AN specimens, whilst longer annealing time resulted in the thicker hardened layer. It is considered that the solid solution of nitrogen into the matrix, the precipitation of needle-like $\alpha$-phases and the precipitation of $\mathrm{TiN}$ resulted in the enhancement of the hardness. Although the re-solution treatment decreased hardness of AN specimens, the hardened layer still had the depth of $1 \mathrm{~mm}$.

Table 1: $\quad$ Mechanical properties.

\begin{tabular}{|c|c|c|c|c|c|}
\hline Material & $\begin{array}{c}\text { Proof } \\
\text { stress } \\
\sigma_{0.2} \\
(\mathrm{MPa}) \\
\end{array}$ & $\begin{array}{c}\text { Tensile } \\
\text { strength } \\
\sigma_{\mathrm{B}} \\
(\mathrm{MPa}) \\
\end{array}$ & $\begin{array}{c}\text { Elongation } \\
\begin{array}{c}\delta \\
(\%)\end{array} \\
\end{array}$ & $\begin{array}{c}\text { Reduction } \\
\text { of area } \\
\varphi \\
(\%) \\
\end{array}$ & $\begin{array}{c}\text { Elastic } \\
\text { modules } \\
E \\
(\mathrm{GPa}) \\
\end{array}$ \\
\hline ST & 882 & 896 & 23 & 41 & 62 \\
\hline AN-0.5h & - & 722 & 7 & 6 & 48 \\
\hline AN-RST & - & 637 & 3 & 4 & - \\
\hline
\end{tabular}

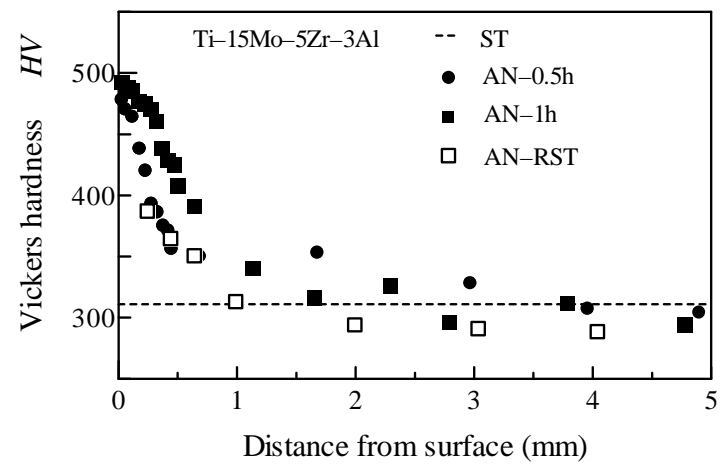

Figure 4: $\quad$ Hardness profiles. 


\subsection{Fatigue strengths}

Figure 5 indicates the $S-N$ curves of the base metal, AN-0.5h and AN-RST specimens. The AN-0.5h specimens exhibited lower fatigue strengths than the base metal. Fatigue fracture surfaces near crack initiation sites in the base metal and AN-0.5h specimens are revealed in Fig. 6(a) and (b), respectively. The fracture surface of the base metal is covered by small facets, indicating that cyclic slip deformation brought about fatigue crack initiation, and transgranular crack propagate occurred. In the AN specimen, however, intergranular crack propagation resulted in the large facets (Fig. 6(b)). The brittle fracture surface morphology along grain boundaries was also observed in AN specimens under quasi-static tensile fracture mode. Figure 7 shows the EDX analysis of AN-0.5h specimen, where the right-hand figure represents the nitrogen intensity of the left-hand SEM image near the specimen surface. It was found that nitrogen distributed along grain boundaries, indicating that TiN precipitated along grain boundaries. This result corresponds to the white lines recognized along the grain boundaries as shown in Fig. 3(a). Consequently, it is considered that the brittle fracture of hard and thin TiN layer along grain boundaries resulted in the intergranular crack propagation and the lower fatigue strengths of AN specimens than the base material.

The fatigue strengths of AN-RST specimens are also plotted in Fig. 5. As shown in Figs 5 and 7, thin TiN layer had detrimental effect on the fatigue strengths. Thus the re-solution treatment was applied to the AN-0.5h specimens in order to re-dissolve TiN precipitates. However, the fatigue strengths of AN0.5h and AN-RST are nearly the same. Figure 6(c) shows the fracture surface near the crack initiation site in the AN-RST specimen. The brittle fracture mode seen in the AN-0.5h specimen (Fig. 6(b)) was not recognized, indicating that the precipitates were dissolved. However, the fatigue strengths of the AN-RST specimens were lower than those of the base metal, and thinner TiN layer than

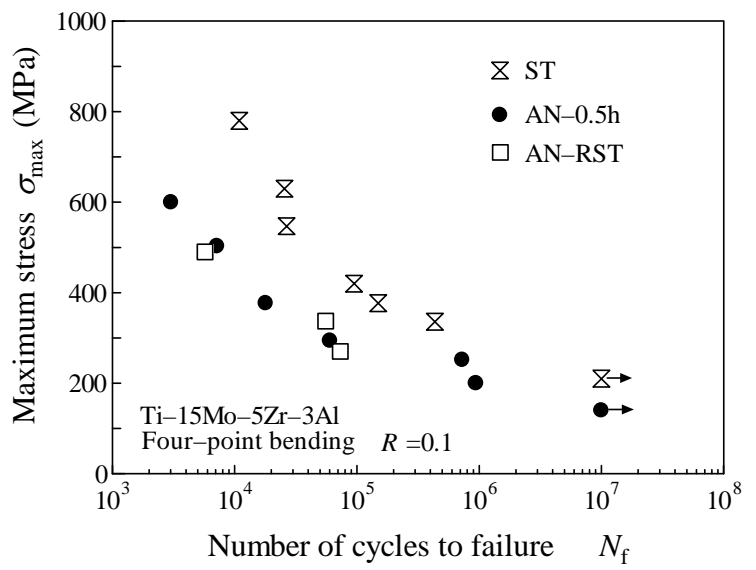

Figure 5: $\quad S-N$ diagram. 
the AN-0.5h specimen was still recognized as shown in Fig. 3(b) after resolution treatment. It is considered that the re-solution treatment could not fully dissolve TiN precipitates, and consequently the fatigue strengths was not increased due to the brittle fracture of TiN.

\section{Conclusions}

In this study, bulk $\beta$-titanium alloy was annealed in nitrogen gas at $1473 \mathrm{~K}$ and re-solution treated at $1127 \mathrm{~K}$ to improve surface hardness. Four-point bending fatigue tests had been conducted using annealed and re-solution treated
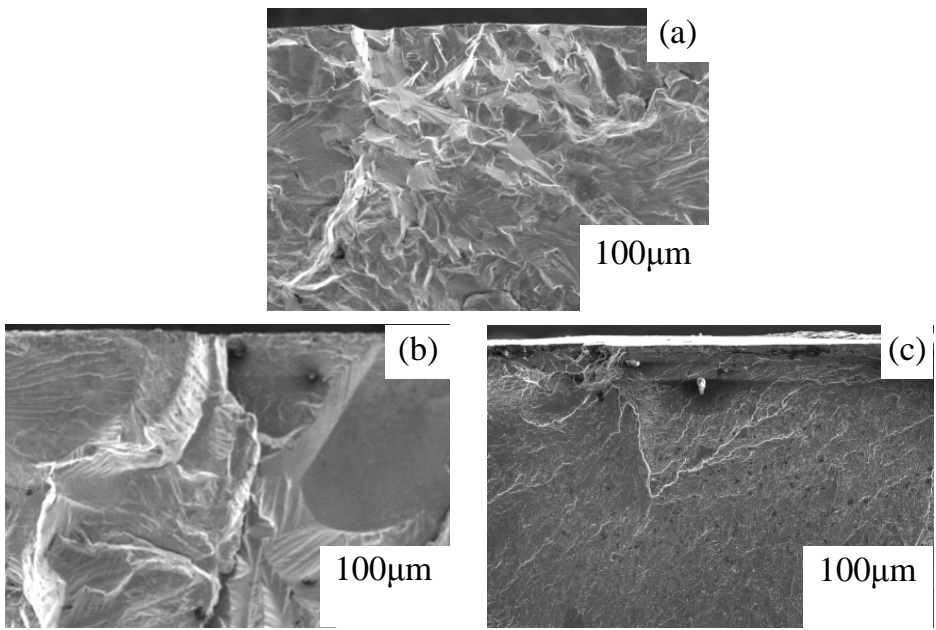

Figure 6: $\quad$ SEM micrographs showing crack initiation site:

(a) ST $\left(\sigma_{\mathrm{a}}=336 \mathrm{MPa}, N_{\mathrm{f}}=4.3 \times 10^{5}\right)$,

(b) AN-0.5h $\left(\sigma_{\mathrm{a}}=377 \mathrm{MPa}, N_{\mathrm{f}}=1.8 \times 10^{4}\right)$,

(c) AN-RST $\left(\sigma_{\mathrm{a}}=336 \mathrm{MPa}, N_{\mathrm{f}}=5.6 \times 10^{4}\right)$.

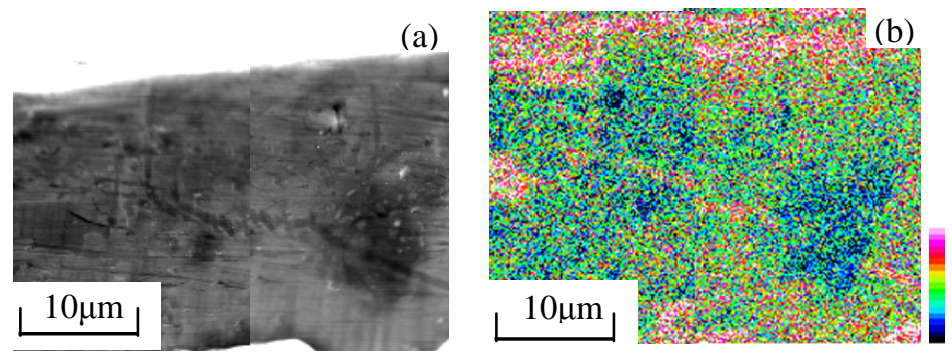

Figure 7: $\quad$ EDX analysis of AN-0.5h near surface:

(a) SEM image, (b) distribution of nitrogen. 
specimens, and the effect of surface treatments on the fatigue properties were discussed. The results obtained are as follows.

(1) Thin TiN layer was formed on the specimen surface and along grain boundaries by the annealing in nitrogen gas. Widmannstaetten structure consisting of needle-like $\alpha$ and $\beta$-phases was formed under the TiN layer. Resolution treatment thinned TiN layer and thickened the layer with Widmannstaetten structure.

(2) The surface hardness was well increased by the annealing in nitrogen gas from $311 \mathrm{HV}$ to about $480 \mathrm{HV}$. The re-solution treatment lowered the hardness.

(3) The specimens annealed in nitrogen gas exhibited lower tensile and fatigue strengths than the base metal. The brittle fracture of hard and thin TiN layer along grain boundaries had detrimental effects on the strengths.

(4) The tensile and fatigue strengths of the re-solution treated specimens were still lower than those of the base metal. The re-solution treatment could not fully dissolve TiN precipitates.

\section{References}

[1] Nakamura, N., Takaki, S., ISIJ International, 36(7), pp. 922-926, 1996.

[2] Nakanishi, T., Tsuchiyama, T., Mitsuyasu, H., Iwamoto, Y., Takaki, S., Materials Science \& Engineering, A460-461, pp. 186-194, 2007.

[3] Tsuchiyama, T., Fujii, Y., Terazawa, Y., Nakashima, K., Ando, T., Takaki, S., ISIJ International, 48(6), pp. 861-867, 2008.

[4] Ando, T., Nakashima, K., Tsuchiyama, T., Takaki, S., Materials Science \& Engineering, A486, pp. 228-234, 2008. 